\title{
ELEMENTOS PARA UNA NUEVA SÍNTESIS EN LOS ESTUDIOS SOBRE LAS ORGANIZACIONES SINDICALES ARGENTINAS BAJO EL GOBIERNO MILITAR (1976-1983)
}

\author{
ELEMENTS FOR A NEW SYNTHESIS IN THE \\ STUDIES OF ARGENTINE TRADE UNIONS \\ UNDER THE MILITARY GOVERNMENT (1976- \\ 1983)
}

LUCIANA ZORZOLI IdICHS-CONICET

\section{Resumen}

En este trabajo se analizan las interpretaciones clásicas en las Ciencias Sociales sobre las transformaciones vividas por las organizaciones sindicales durante el gobierno cívico militar autodenominado "Proceso de Reorganización Nacional" que gobernó el país entre 1976 y 1983 con el fin de identificar aspectos problemáticos que las mismas legaron al campo de estudios.

A partir de allí se cuestionará su utilización actual y se señalarán temas desatendidos que debieran ser considerados para una nueva síntesis sobre los efectos que tuvo la restructuración social vivida durante la última dictadura.

Palabras clave: Sindicatos, Dictadura Militar, Argentina.

\begin{abstract}
This paper examines classical interpretations in the field of Social Science of the changes experienced by trade unions during the self-named "Proceso de Reorganización Nacional" military government which ruled the country between 1976 and 1983. This aims to identify problematic areas which have been passed on to this area of study.

Its current use shall then be questioned and neglected issues that should be considered will be highlighted in order to build a new synthesis on the effects of the social restructuring experienced during the last dictatorship.
\end{abstract}

Keywords: Trade Unionds, Dictatorship, Argentina. 


\section{INTRODUCCIÓN}

Se ha calificado muchas veces a las transformaciones sucedidas en América Latina desde los años setenta como "copernicanas". Centrándonos en el caso argentino puede afirmarse que los cambios producidos en el país en la década que va desde el fin de la proscripción del peronismo y el retorno de Perón hasta el comienzo del gobierno democrático de Raúl Alfonsín bien pueden entenderse de esa manera. Debe tenerse en cuenta que si bien desde 1930 las intervenciones militares fueron una constante en el régimen político argentino, las intenciones refundacionales de los altos mandos de las Fuerzas Armadas (FFAA) cuando tomaron el poder el 24 de marzo de 1976 se convirtieron en un punto de inflexión de la historia nacional. Desde entonces, los esfuerzos hechos por las Ciencias Sociales se orientaron a explicar en qué medida el autodenominado "Proceso de Reorganización Nacional" (PRN) imprimió cambios cualitativos a la estructura económica y social del país destinados a perdurar más allá de los siete años y ocho meses que esa dictadura cívico militar gobernó el país.

Desde mediados de los años cuarenta y hasta entonces, el modelo de acumulación vigente se había articulado en torno al desarrollo de una industrialización orientada al mercado interno que integró, no sin resistencias y conflictos, a la clase trabajadora en un proyecto político nacional liderado por Juan Domingo Perón. El crecimiento industrial, la integración social con movilidad ascendente en el marco de la ciudadanización política de la clase obrera y la formación de un partido político de masas al frente del Estado no trajeron, sin embargo, estabilidad al sistema político argentino. A partir de su primer gobierno (1946) y especialmente desde su segundo mandato en 1952, el peronismo fue percibido por los sectores dominantes como un riesgo para el país cuya orientación "totalitaria" atentaba contra el desarrollo capitalista y liberal. Desde esa posición las 
conquistas sociales, los derechos laborales y el modelo de acumulación basado en la industrialización por sustitución de importaciones que tenía en los sindicatos un polo clave del sistema sociopolítico eran una tríada que debía desarticularse, aunque la fórmula para hacerlo resultó mucho más difícil de consensuar de lo que creían los militares que derrocaron a Perón en 1955.

Entre 1955 y 1973, año en el que el peronismo retornó al poder después de una extensa proscripción, la sucesión de gobiernos militares y civiles demostró la incapacidad de las dos clases sociales fundamentales de la sociedad argentina de superar lo que Portantiero llamó un empate hegemónico. La clase dominante no pudo, proscribiendo o limitando al peronismo, reorganizar el país ni hacer olvidar el "hecho maldito" de la historia nacional. Los trabajadores tampoco pudieron durante todos esos años reinstalar en el poder un gobierno que consideraran propio aunque mantuvieron altos niveles de organización y de cohesión política que, basados en una fuerte conciencia de su importancia, impidieron la estabilización de proyectos que los excluyeran.

Fue esa persistente organización obrera la que permitió a los sindicatos mantener su lugar central en la política argentina y la que desde mediados de los años sesenta hizo que sectores de la clase trabajadora se radicalizaran y entraran en contacto con otras franjas juveniles movilizadas. El crecimiento de una "nueva izquierda" en Europa y en América había alentado dentro y fuera del peronismo cuestionamientos al orden social imperante y una determinación cada vez mayor a enfrentar los planes del liberalismo económico buscando el retorno de Perón. De hecho fueron las jornadas de protesta contra los planes del gobierno militar de la "Revolución Argentina" conocidas como Cordobazo y Rosariazo las que marcaron el cambio de clima, produciendo la desarticulación del gobierno militar en un ataque en el que confluyeron con la clase trabajadora sectores de la intelectualidad, el estudiantado y de las juventudes provenientes de las clases medias urbanas (Brennan \& Gordillo, 2008; Schneider, 2005). En las bases de esa desarticulación se encontraban procesos más profundos: el surgimiento de un peronismo radicalizado que enhebraba el retorno de Perón con una "patria socialista", la aparición de organizaciones revolucionarias que reivindicaban la lucha armada para conseguir la transformación radical de la sociedad y la creciente actividad en el lugar de trabajo de sectores obreros (Basualdo, 2008). Esos sectores de la clase trabajadora combinaron actividad política de base con una creciente crítica a las estrategias "moderadas" de la dirigencia sindical agrupada en la Confederación General del Trabajo (CGT), minando aún más la capacidad de respuesta de un régimen político desgastado por el sostenimiento de una larga e infructuosa 
proscripción.

Las elecciones que permitieron el retorno del peronismo al poder en mayo de 1973 con la elección de Héctor José Cámpora como presidente ampliaron las expectativas sociales. Lejos de poder encauzar el proceso de movilización social abierto, el peronismo se vio atravesado por la creciente confrontación entre dos estrategias que se encontraban aún en construcción. El desplazamiento de Cámpora en julio de 1973 y la elección democrática de Perón como presidente en una fórmula con su esposa, María Estela Martínez de Perón, no sirvió tampoco para producir esa reorientación, ni siquiera cuando Perón decidió enfrentar al ala izquierdista de su propio movimiento y promover un pacto social en el que la clase obrera moderara sus demandas, respetara a su dirección "histórica" y se integrara en un acuerdo nacional con el empresariado. El fallecimiento de Perón en julio 1974 y la asunción de su esposa como presidenta alteraron aún más el escenario político. Lo que siguió fue un período de maduración de los conflictos sociales cuyo único rumbo claro era una nueva intervención militar.

Mientras desde una débil presidencia María Estela Martínez de Perón intentaba aplicar planes de ajuste económico y enfrentaba a la izquierda radical, las FFAA y los sectores dominantes del país comenzaban a discutir los planes para su reemplazo (Novaro \& Palermo, 2003, pp. 19-36). La promoción de bandas paramilitares de ultraderecha y la autorización a los militares para que "exterminaran" a los grupos guerrilleros en una guerra contrainsurgente no fueron suficientes para contrarrestar su inestabilidad constitutiva. Para forzar su desplazamiento se selló un acuerdo cívico militar con el empresariado nacional y sectores de las dirigencias sociales y políticas que contaba con la mirada oficiosa de actores claves como la embajada de los Estados Unidos y algunos países vecinos. Sin apuro se amplificaron los problemas económicos y se dio rienda suelta a la inflación al mismo tiempo que las acciones de las organizaciones político militares de izquierda y los ataques de los grupos de ultraderecha eran expuestos como prueba de los riesgos de desintegración social y nacional que supuestamente vivía el país. Usando y produciendo el caos económico y la violencia, los altos mandos militares y sus aliados civiles construyeron el consenso inicial para derrocar al peronismo e implementar un plan de "reorganización" económica y social.

Los objetivos que proclamaba el nuevo gobierno militar organizado en torno a las FFAA eran los de reorganizar la economía del país eliminando las bases que habían permitido el crecimiento del "populismo" y disciplinar al conjunto social exterminando a la juventud revolucionaria y a los sectores combativos del movimiento obrero para fundar un régimen que se ubicara por encima del régimen político de modo que los militares pu- 
dieran de allí en más controlar a la sociedad y la política argentina como garantes últimos de la nación (Canelo, 2008, 2016; Quiroga, 1994). La aplicación de ese plan y la conquista de esa nueva hegemonía implicaba el exterminio de aquellos considerados agentes de "la subversión" a partir de una imprecisa y cambiante definición. ${ }^{1}$

El plan represivo estaba dirigido contra los sectores movilizados de la sociedad argentina en un sentido amplio. La víctima publicitada eran en primer término los miembros de las organizaciones político militares (los 'guerrilleros') y los sectores que constituían la periferia de esas organizaciones. Más allá de las presentaciones discursivas la represión se orientó desde un primer momento tanto contra esas organizaciones como contra los sectores del movimiento obrero que protagonizaban el proceso de radicalización política: el clasismo, la izquierda y el denominado 'peronismo revolucionario'. Esto en el marco de una reestructuración económica que era acompañada con la imposición de un orden social rígido, que a la larga no protegió al gobierno del desarrollo de crisis sucesivas, su agotamiento y finalmente su descomposición producida por factores tanto internos como externos.

El objetivo de este trabajo consiste en exponer algunos elementos desatendidos en el estudio de las relaciones entre los sindicatos y el gobierno militar (1976-1983) con el fin de aportar a la construcción de una nueva síntesis. En ese sentido la primera sección del artículo presentará un estado de la cuestión para entender cómo se construyó la interpretación dominante en las Ciencias Sociales sobre el tema deteniéndonos en los autores principales, para presentar a continuación nuestra crítica, con los argumentos que permiten matizar esas interpretaciones aún dominantes, proponiendo vías de exploración nuevas.

1 Parte de la "guerra contra la subversión" se desarrolló a plena luz del día y fue ampliamente publicitada como "combates y enfrentamientos" contra las fuerzas "subversivas" o "terroristas". La otra parte del plan de exterminio implicó el secuestro de personas por grupos militares o policiales, el traslado de las y los secuestrados a los más de quinientos centros clandestinos de detención donde eran sometidos a vejámenes y torturas y en algún momento variable, eran asesinados y ocultados sus cuerpos para mantener su condición de "desaparecidos". Como parte de ese exterminio los militares realizaron también un plan sistemático de apropiación y robo de niñas y niños con aquellos nacidos en cautiverio o que se encontraban con sus padres en el momento de su secuestro, algo que convirtió la lacerante herida de las desapariciones en un presente permanente que no puede cerrarse sin la restitución de la identidad de cada uno de ellos (Perez \& Di María, 2007). 


\section{EL ESTUDIO DE LAS TRANSFORMACIONES EN EL MUNDO SINDICAL BAJO LA DICTADURA Militar: desafíos Y PROblemas Para las Ciencias SOCIales}

Como se señaló el diagnóstico que justificaba la irrupción militar en 1976 fue compartido por los militares y los sectores dominantes aunque la aplicación de las medidas que "terminarían con el desorden" producido por una sociedad movilizada y demandante generó más de una vez fricciones en el interior de la coalición golpista. Las críticas de mayor envergadura fueron las producidas por las medidas económicas del ministro José Alfredo Martínez de Hoz y no las dirigidas contra la política represiva, que ganaron legitimidad en forma paulatina y a contra corriente.

Tomando como punto de partida esa dinámica general Francisco Delich sostuvo tempranamente que durante el PRN había primado la quietud obrera y se había producido un debilitamiento sindical en el marco de una transformación fenomenal de la economía del país (1982). ${ }^{2}$ Su tesis encontró respuestas inmediatas de quienes destacaban el peso de la oposición obrera a la dictadura y la permanencia del carácter combativo de la clase trabajadora pero también contó con múltiples adherentes que aunque moderaron en parte la afirmación sobre la quietud obrera mantuvieron aquello del debilitamiento sindical.

En su trabajo Delich proponía una genealogía del poder de la clase obrera y de la burguesía industrial que veía fundado en el modelo de industrialización por sustitución de importaciones. En el desarrollo de éstas dos fuerzas sociales, sostenía, se había presentado una "paradoja de asimetría" en la envergadura que poseerían como clases sociales antagónicas. La burguesía industrial se caracterizaba para Delich por ser "raquítica en términos de capital y poder" y la clase obrera por ser "fuerte, numerosa y combativa" (1982, p. 132). Pese a la paradoja ambas habrían tenido la misma estrategia de fortalecimiento: "la reivindicación corporativa", pero la burguesía industrial no habría sido capaz de "articular la sociedad urbana" y por lo tanto de disputar para sí el poder político constituyéndose en un confuso referente que condicionó por su carencia de liderazgo la

2 En simultáneo a la publicación de los trabajos de Delich se publicó el volumen Sindicalismo y Regímenes militares en Argentina y Chile editado por Bernardo Gallitelli y Andrés Thompson desde el Centre for Latin American Research and Documentation (CEDLA) de la Universidad de Amsterdam como resultado de un seminario realizado en octubre de 1981 (ver Introducción Gallitelli \& Thompson, 1982, pp. 7-9). En el libro tres artículos analizaban la situación del sindicalismo argentino bajo del régimen militar desde una perspectiva distinta a la propuesta por Delich, el primero pertenecía a Ricardo Falcón, el segundo a Gallitelli y Thompson y el tercero a Ronaldo Munck. 
conducta obrera y sindical (1982, p. 133). El escenario quedaba constituido por "un Estado cada vez más fuerte y más centralista" una sociedad "cada vez más débil" y un conjunto de organizaciones corporativas "ambivalentes" que eran el marco del golpe militar de 1976, constituido como un acto reactivo de las fuerzas militares en el marco de una sociedad en "convulsión profunda" al que se sumaba el repliegue del sector industrial (Delich, 1982, p. 133). ${ }^{3}$ Se instalaban desde ese momento dos vacíos, sobre el vacío políico inaugural un vacío social producido por la clausura del espacio de las organizaciones corporativas, silenciando los conflictos posibles y beneficiando el poder de clase de la burguesía cuando esta se recomponía, diversificaba y reestructuraba al calor del nuevo modelo económico. Simultáneamente los sindicatos que habían alcanzado "el máximo poder corporativo que jamás hayan registrado" en el período 1973-1976, vivían desde 1976 y hasta 1980 con el "mínimo poder imaginable" de la historia moderna. La respuesta a éste abrupto cambio debía buscarse en "los efectos de la acción estatal sobre la clase obrera y sus sindicatos", fusión que le permitió a Delich "explicar" lo sucedido a trabajadores y organizaciones dentro de su hipótesis general de inactividad. ${ }^{4}$

Poco después, en 1984, se publicó en Buenos Aires el primer libro que analizó en forma integral y cuando ya había finalizado el gobierno militar la cuestión de los sindicatos. Las organizaciones sindicales y el poder militar (1976-1983) de Álvaro Abós se convirtió desde entonces en un pilar de los estudios sobre el tema, tanto que su influencia se extiende hasta nuestro

3 Había adelantado Delich que esas FFAA se habían "separado cada vez más de la sociedad" gravitando "verticalmente" en las confrontaciones producidas en el seno de la sociedad (1982, p. 132). Otras posiciones sobre la relación entre FFAA y sociedad puede verse en Rouquié (1982) López y Pion Berlin (1996) y Canelo (2008).

4 En octubre de 1981, después de haber enviado para su publicación "Después del diluvio, la clase obrera" Delich participó de un coloquio sobre "Los problemas de la Argentina" organizado por la Arbeitsgemeinschaft Deutsche Lateinamerikaforschung (ADLAF) presentando una ponencia en el mismo tono titulada "Desmovilización social, reestructuración obrera y cambio sindical" que fuera publicada en 1982 (Waldmann \& Garzón Valdés, 1982). Por entonces se publicaron también otros trabajos que partían de aceptar la propuesta del Delich e indagaban en las consecuencias de ese "inmovilismo", como el de Bialakowsky, Micieli y Kohan (1986). Las réplicas tampoco se hicieron esperar, bosquejando las dos posiciones que organizarían los debate hasta nuestro días. Primero fue León Bieber (1982) quien cuestionó las premisas expuestas por Delich acercándose a las ideas que pocos meses antes habían apuntado Ricardo Falcón y Ronaldo Munck en el libro editado por CEDLA (ver Gallitelli \& Thompson, 1982) haciendo eje en la resistencia y oposición de los trabajadores a los planes del "Proceso". Como se verá el antagonismo entre dos paradigmas, unos con eje en la quietud y otro en la oposición estaba en proceso de construcción. 
días. El libro articuló una respuesta, por momentos contradictoria, sobre lo sucedido con los sindicatos mezclando en su exposición la actuación "sindical" (presumiblemente como sinónimo de la de la dirigencia sindical peronista ortodoxa) con actitudes de otros sectores como los dirigentes sindicales exiliados o de sectores de base. ${ }^{5}$ En su propuesta fue central la organización que propuso del período dividiéndolo en dos etapas: una primera que estaría signada por la inmovilidad y una segunda donde Abós sostuvo que se superó "el repliegue" vivido y comenzó la actividad sindical que convirtió al sindicalismo "en el auténtico antagonista del régimen". De este modo y siempre siguiendo a Abós, entre 1976 y 1979 la pasividad habría dominado el escenario político producto de un "corsé represivo" que impidió a los sindicatos actuar contra el régimen militar o sobrepasar "los límites de un consenso", aceptando las ideas de Delich aunque no en forma explícita. A partir de allí y más específicamente desde la Jornada Nacional de Protesta de abril de 1979 convocada por un sector de esa dirigencia sindical -denominado "Comisión de los 25"- el repliegue habría transmutado en antagonismo comenzando un ciclo de oposición que sólo tendría fin con el retiro militar en diciembre de 1983 (ver 1984, pp. $42-47$ y «Balance de una travesía en el desierto» p. 95-109). Estas dos etapas propuestas por Abós cristalizaron como articuladoras de las explicaciones sobre qué habían hecho y qué había pasado con los sindicatos en aquellos años y pueden encontrarse aún hoy en la mayor parte de los trabajos sobre el período.

Solo un año más tarde se publicó Las prácticas sociales del sindicalismo (1976-1983) de Arturo Fernández que a diferencia del trabajo de Delich y Abós contenía una elaboración más compleja de la situación vivida entre 1976 y 1983 y partía de una diferenciación analítica clave de la que carecían los trabajos anteriores: la situación y posiciones de los sectores obreros, incluso de los movilizados, no era equiparable a la de la dirigencia sindical peronista. Además la restructuración vivida no sólo afectaba la posición obrera en su relación con la clase dominante también implicaba cambios significativos al interior de las organizaciones de trabajadores. Pero pese a sus múltiples aciertos, entre los que se destaca haber analizado la política económica y laboral del PRN abordando no sólo los aspectos represivos, la propuesta de Fernández no logró reordenar los estudios sobre este período.

5 Varios referentes del sindicalismo "combativo" se habían visto obligados al exilio y desde él organizaron una sistemática denuncia de lo que estaba sucediendo en Argentina que los diferenció de lo sostenido por los dirigentes sindicales "ortodoxos" en el exterior. Ver entre otros Basualdo (2007) y Dawyd (2014). 
El desarrollo del debate se potenció con un libro de Pablo Pozzi que volvía a debatir en los términos del paradigma propuesto por Delich y que había sido sostenido parcialmente por Abós, pero desde la posición opuesta a la del inmovilismo, la de la oposición. ${ }^{6}$ En "La oposición obrera a la dictadura. 1976-1982" (1988) puede encontrarse una refutación fundada a la tesis de Delich, indicando que la actividad de la clase obrera no había estado ausente y que una adecuada indagación histórica encontraría que sectores de la clase trabajadora se habían opuesto a la transformación deseada por el PRN limitando sus conquistas y modificando incluso algunos de sus objetivos. La posición sostenida en el libro era también una trinchera de defensa de la comprensión clasista de la sociedad que sostenía como vigentes los lineamientos generales dados por el marxismo para comprender la formación de las clases sociales y su antagonismo en la sociedad capitalista, algo que Pozzi intuía -con razón- subyacía en la discusión abierta.

De hecho, las políticas de la memoria sobre la dictadura y especialmente sobre quienes eran las y los desaparecidos que estaba volviéndose hegemónica en la sociedad argentina a finales de la década del ochenta se alzaba contra Pozzi sosteniendo a Delich. Como señalan Juan Besse y Miriam Wloslo (2013) en ese proceso de construcción de la memoria se había desplazado a los trabajadores como sujetos de la represión y a su militancia política como razón de la misma producto de una política de olvido que optimizó la defensa de las y los desaparecidos a costa de la precisión histórica, invisibilizando el conflicto social y las luchas del período inmediato anterior y aceptando como conclusión colectiva el Nunca Más ${ }^{7}$

6 Si consideramos que el debate entre inmovilismo y oposición era colindante con otros más generales de fines de los años ochenta sobre los nuevos sujetos sociales y la perdida de centralidad de la clase obrera, se comprende la razón del retorno y su valor se realza. Esto porque no puede hacerse una valoración abstracta del desarrollo de éste ni de ningún debate pues equivaldría a negar que la misma producción académica se da en el marco de una producción socioeconómica, política y cultural de la que no es ajena y en la que interviene. Se trataba de saber qué había pasado con la clase obrera y los sindicatos bajo la dictadura pero también y cada vez más qué entendían las Ciencias Sociales y la sociedad argentina sobre qué podía hacer la clase obrera en el contexto de una ofensiva como fue la ofensiva neoliberal.

7 Se trata de un informe sobre los crímenes del PRN basado en el trabajo de la Comisión Nacional sobre la Desaparición de Personas (CONADEP) creada por el presidente Alfonsín. Sobre el informe puede verse Crenzel (2008) y un análisis específico sobre como se representaron las y los obreros desaparecidos en el mismo, en Crenzel (2013). 
y la teoría de "los dos demonios"8 que oscurecían el carácter de clase del PRN.

La respuesta estructurada por Pozzi consideró que si bien se habían producido cambios significativos manu militari, estos no buscaban sólo cambios económicos sino también transformaciones en la esfera social, ideológica y política de la sociedad argentina. ${ }^{9}$ Es en el análisis de los resultados de esas "transformaciones" que el éxito del PRN es juzgado como un éxito relativo producto de la tenaz oposición obrera de base. Es que organizado en torno a un objeto mejor definido el libro de Pozzi visibilizó que la actividad de los trabajadores no sufrió una "inmovilización" como la señalada por Delich, aunque centraba mayormente su atención en la actividad de base sin indagar en sus vínculos con las organizaciones sindicales y sus direcciones y pese a que los ejes de la esa oposición desplegada no eran analizados con especial profundidad. El libro de Pozzi tuvo sin embargo un punto de contacto con Abós a partir de la periodización de ese "segundo período" en la relación entre sindicatos y gobierno militar (1979-1983) entendido como un proceso de desgaste sistemático que concluyó con el retiro militar aunque uno lo adjudique a la presión y persistencia de las bases y el otro al heroísmo de sectores de la dirigencia sindical peronista. Esta confluencia colaboró sin duda en que la periodización en sí misma se haya vuelto canónica.

Un análisis de los ciclos de conflicto del período y gran parte de las publicaciones que abordan la historia política del PRN muestran que la imagen de una oposición continua desde 1979 y hasta 1983 es una simplificación excesiva, no sólo por el poder que retenían aún los militares en ese segundo período, sino por el escaso dinamismo de los sectores políticos en general amén de las posiciones heterogéneas y por momentos ambiguas de los sectores de la dirigencia sindical ortodoxa sobre las formas que debía tomar la futura institucionalización del país (Canelo, 2008; Novaro \& Palermo, 2003; Quiroga, 1994).

8 Se denomina "teoría de los dos demonios" a la concepción, promovida entre otros por la iglesia católica y el gobierno de Raúl Alfonsín (1983-1989), según la cual la violencia ejercida por las FFAA durante la dictadura cívico militar fue "equiparable" con los actos de violencia llevados adelante por organizaciones político militares, como Montoneros o el Ejército Revolucionario del Pueblo. La literatura sobre la construcción de esa política de la memoria, sus tensiones y sus cambios en las últimas cuatro décadas ha tenido un importante crecimiento acompañando la crítica a ese primer consenso. Entre otros trabajos destacados se encuentran los de Jelin y abordando los efectos de ese consenso específicamente sobre los trabajadores en la década del ochenta Molinaro (2013). 
Como se señaló, el libro de Pozzi hubiera constituido el fin del debate entre inmovilismo y oposición sino fuera porque en las inmediaciones de la tesis del inmovilismo empezaron a resguardarse quienes sostenían que las transformaciones sucedidas durante la última dictadura, ya no importaba tanto cuáles ni cómo habían sido, debían entenderse como el fin de la centralidad obrera en la sociedad. A partir de esa premisa los estudios sobre trabajadores y dictadura fueron cada vez más marginales en los estudios sociohistóricos sobre el pasado reciente y si se mantuvieron fue sosteniendo el paradigma de la oposición contra el de inmovilismo a costa de una síntesis que permitiera integrar de forma más consistente y articulada los distintos aspectos de la transformación vivida.

\section{HACIA UNA NUEVA SíNTESIS}

Pese a que existe una persistencia del enfoque problemático que establecieron los primeros estudios sobre el tema y que los mismos son citados como referencia cuando se aborda este período, una serie de investigaciones en los últimos años indican que estamos frente a una cambio de aproximación. ${ }^{10}$ Como parte de esas aproximaciones abordaremos en este apartado algunos aspectos que debieran considerarse para una nueva síntesis.

Como se mencionó uno de los legados más conflictivos de los trabajos "clásicos" sobre lo sucedido en el mundo sindical durante el PRN se en-

9 En este aspecto Pozzi toma lo planteado por Juan Villarreal aunque las conclusiones de ambos tienen aspectos contradictorios, especialmente en tanto que Villarreal (1985) plantea que el golpe militar va a producir una "homogeneización" de las clases dominantes y una "heterogeneización" de los sectores populares para destruir los lazos de solidaridad de clase por medio transformaciones socioeconómicas tanto como por medio del terror y Pozzi sostiene que esto, más allá de las intenciones dictatoriales, no sucedió.

10 Entre otros pueden verse los trabajos de Rodríguez (2008), Ghigliani (2011) Dicósimo y Caminati (2013) e Iramain (2014). Son destacados los aportes de Basualdo (2006a, 2008) que han sumado como objeto la actividad internacional de exiliados sindicales (Basualdo, 2007; y Dawyd, 2014) y la esfera internacional de la actividad sindical argentina (2006b, 2010). Un intento de síntesis de los elementos planteados a partir de un estudio de caso puede verse en los trabajos de Lorenz $(2007,2013)$ y en los de Dicósimo (2006) y Dicósimo y Soul (2013), que indagan en las relaciones al interior de los sindicatos entre trabajadores y direcciones sindicales durante éstos años. Los aportes de Bretal sobre los vínculos entre trabajadores que no eran "ni militantes político-partidarios ni delegados gremiales" (2011) se suman a estas nuevas aproximaciones como aquellos que abordan los procesos de "normalización sindical" dedicándose a los últimos años del PRN y a los primeros del gobierno democrático de Raúl Alfonsín (Arriaga, 2012; Gordillo, 2013, 2016; Massano, 2012; Molinaro, 2016; Sangrilli, 2010; Zorzoli, 2015). 
cuentra en la fusión de distintos sectores sindicales en parte o en todo el período. Por el contrario reconocer las diferencias permite identificar sectores asociados a proyectos sindicales en disputa, en términos generales los defensores de un modelo sindical piramidal y fuertemente verticalista (la dirigencia sindical peronista ortodoxa) que defendía intereses sectoriales o "corporativos" y se había constituido en hegemónica entre los años sesenta y setenta (Dawyd, 2011) y los sectores que cuestionaron esos objetivos sindicales tanto desde el marxismo como desde el peronismo (los denominados combativos), que incorporaron métodos de organización y participación democráticos y directos contra los delegativos y restrictivos de los ortodoxos. ${ }^{11}$

Las implicancias de esa fusión son múltiples pues impidió -y aún hoy impide- un análisis de mayor profundidad de los distintos actores y de sus relaciones durante la dictadura, tanto con el gobierno como de las que se dieron al interior de los sindicatos (entre los sectores que estaban siendo perseguidos, las bases obreras y las dirigencias) o entre sectores de esa dirigencia sindical hegemónica y grupos críticos o opositores.

Sumado a esto debe considerarse como problemática la periodización que planteara Abós en tanto que separa las "actitudes sindicales" en aquellas que van desde 1976 a 1979 y de la Jornada de Protesta de abril de 1979 a diciembre de 1983. Paradójicamente además, desde las indagaciones mencionadas hasta hoy los estudios históricos tienen a perder profundidad y precisión en los años finales de la presidencia de facto del general Videla y durante las presidencias de facto de Viola entre marzo de 1981 y diciembre de 1981; de Galtieri entre diciembre de 1981 y junio de 1982 y finalmente de Bignone entre julio de 1982 y diciembre de 1983, esto a pesar que en ellos se sostiene que es en ese segundo período donde podría encontrarse el despliegue de actividad sindical más significativo y que allí suceden dos "hitos" en materia de transformación de las organizaciones sindicales: la sanción y aplicación de la nueva ley de Asociaciones Profesionales y la devolución de los sindicatos intervenidos y el comienzo del proceso de "normalización sindical".

En este apartado expondremos algunos elementos que permiten cuestionar la aplicación tanto del paradigma de inmovilismo como el de oposición para explicar lo sucedido con la dirigencia sindical peronista ortodoxa,

11 Téngase en cuenta que esta conceptualización de los sectores sindicales que es generalmente aceptada deja a las "bases obreras" como un tercer grupo, dando espacio para que algunos asuman la "identidad" entre bases y dirigentes y otros "la oposición" entre ellos, algo que sin duda requiere de mejores conceptualizaciones. 
cuestionando también la utilidad de la periodización propuesta por los estudios "clásicos" y que aún hoy es utilizada. Lo haremos a partir de un sintético análisis del posicionamiento inicial de esa dirigencia sindical cuando se produce el golpe militar; de su contribución en sostener la idea de que el país sufría "ataques externos" y por último ofreciendo una aproximación crítica a la actividad de la dirigencia sindical en el período más subestimado en los estudios sobre el tema, aquel que va de 1979 a 1983. Este análisis permitirá entrever que ni la quietud ni la oposición expresan síntesis adecuadas de lo sucedido y actuado por este sector del mundo sindical, poniendo de manifiesto la necesidad de profundizar los estudios sobre este período.

Como punto de partida es necesario señalar que las relaciones entre el gobierno militar y los sindicalistas agrupados en la CGT se vieron definidas por un contexto de ofensiva general sobre el trabajo que a partir del 24 de marzo posibilitó el despliegue de un extenso plan represivo junto con la instrumentación de una batería de políticas que buscaban disciplinar a los trabajadores y "desmantelar" el poder social de la clase obrera junto con las conquistas obtenidas en los años previos.

Como mencionamos, las medidas contra el mundo sindical tuvieron en ese marco dos ejes: por un lado la represión directa que buscó eliminar a los sectores considerados "subversivos" y por otro la redefinición de los modos legítimos de actuar sindicalmente dirigida a una refuncionalización de las dirigencias sindicales ortodoxas. Con la represión directa el PRN logró imponer una férrea disciplina en el mundo del trabajo asistido por el disciplinamiento que implicaron las detenciones y desapariciones en la imposición de un 'nuevo orden laboral' llevado adelante con acuerdo de gran parte del sector empresario. ${ }^{12}$ Esa represión iba dirigida contra quienes desde posiciones de base o de dirección participaban del sector denominado "combativo" o clasista que había protagonizado la ola de protestas contra el gobierno militar de la "Revolución Argentina" y habían fundado la "CGT de los Argentinos", cuestionando los objetivos sindicales tradicionales e incorporando métodos de organización y participación democráticos y directos contra los delegativos y restrictivos que caracterizaron al peronismo ortodoxo.

12 Los empresarios en muchos casos fomentaron la presencia militar intimidatoria en los lugares de trabajo y llegaron a participar de la planificación y ejecución del plan represivo como demuestra Basualdo (2006a) y el trabajo del Ministerio de Justicia y Derechos Humanos de Argentina junto con el CELS y la FLACSO (2015). 
Por otro lado y tal como aquí se lo entiende, se buscó aleccionar a las dirigencias sindicales ortodoxas utilizando las intervenciones sobre algunos sindicatos y federaciones como amenaza mientras se desarticulaba el espacio que hasta entonces los había organizado, la CGT, que pasaba a manos del gobierno militar. Desde allí se promovió que la actividad sindical se restringiese a la administración interna de las entidades gremiales hasta que el régimen elaborase un proyecto laboral acorde a la refundación planteada, buscando establecer que acción sindical era "legítima" y cual no. ${ }^{13} \mathrm{Si}$ bien la dirigencia sindical no aceptó replegarse a la administración de los sindicatos dejando la esfera pública que los tenía como actores políticos principales desde los años cuarenta, tampoco actuó contra los militares en la instalación de su plan sistemático de exterminio con intenciones de transformación social profunda. Procedía en ese sentido de acuerdo con un principio históricamente construido que aceptaba la participación militar como alternativa ante las crisis de dominación, una participación que funcionaba como una "hegemonía sustitutiva" que produjo lo que algunos autores llamaron la pretorización del sistema político argentino (Quiroga, 1994, p. 37).

Participando de ese consenso inicial la dirigencia sindical peronista se mostró dispuesta aunque fuera temporalmente a aceptar el marco de restricciones a la actividad sindical impuesto por las FFAA proponiéndose "negociar" sobre los plazos de las intervenciones a los sindicatos y federaciones, fiel a la lógica del pragmatismo institucional que describió Daniel James (2006, pp. 179-184). Esa negociación incluía la búsqueda de espacios de participación de ese sector gremial en el PRN, una búsqueda que fue explícita y que no se limitó al momento inicial como podría asumirse a partir de la periodización propuesta por Abós. Por el contrario cuando la dirigencia sindical ya se había organizado en torno a dos grupos estables (la "Comisión de los 25" y la "Comisión de Gestión y Trabajo" que luego se denominó "Comisión Nacional de Trabajo") y posteriormente cuando esos grupos devinieron en "CGT Brasil" y "CGT Azopardo" esa estrategia siguió siendo la dominante, al menos hasta la derrota militar en la guerra de Malvinas en junio de 1982, que marcó la imposibilidad del PRN de reconstruir la hegemonía perdida y dio paso a su crisis final.

13 Los espacios que organizaban a las fuerzas sindicales combativas como las Coordinadoras y el grupo de sindicatos con conducciones no ortodoxas habían sido desarticulados en los años previos, combinando la intervención con la represión y los métodos gansteriles (ver Werner \& Aguirre, 2007). 
Asociada a esa búsqueda de participación es posible visibilizar otro elemento que las lecturas clásicas subestimaron cuando se trataba de analizar la actividad de la dirigencia sindical peronista en el período: la contribución de esa dirigencia sindical a la estabilización del PRN tanto en su establecimiento nacional e internacional como en los años posteriores. Esa contribución, cuyas aristas son múltiples y en las que queda aún mucho por indagar, queda de manifiesto en la omisión sistemática de denunciar o pronunciarse sobre la represión y las desapariciones que estaban llevándose a cabo en los lugares de trabajo y en los barrios obreros, o de indicar como responsables de esos crímenes a los grupos operativos de las tres Fuerzas Armadas. Una muestra de esa contribución a la estabilización y legitimación del régimen puede encontrarse en las acciones internacionales de esa dirigencia, especialmente en las participaciones anuales en las conferencias de la Organización Internacional del Trabajo (OIT). Desde allí el sector ortodoxo se ocupó de confirmar el discurso oficial sobre lo que sucedía en la Argentina aseverando la existencia de "ataques subversivos" y de "problemas internos" mientras actuaba en forma hostil contra las denuncias por la situación represiva (para un análisis de esa colaboración en la instalación internacional de la dictadura argentina ver Zorzoli, 2016b). Incluso cuando la relación de este sector sindical con el gobierno se tensó, primero por el empeoramiento de la situación económica y a partir de noviembre de 1979 por el intento de aplicación de la ley sindical, el silencio sobre el plan represivo no se modificó.

Los matices sobre este punto sin embargo son significativos. Por un lado, porque hubo casos puntuales en que las acciones de esa misma dirigencia fueron objeto de la represión (como en el conflicto que protagonizaron los trabajadores de los servicios eléctricos y en los que actuó protagónicamente la conducción del sindicato Luz y Fuerza) y porque el silencio no fue la única actitud de la dirigencia sindical que ha sido documentada. La participación de sectores de la dirigencia sindical ya sea actuando como parte de los grupos represivos o participando en el señalamiento de los sectores clasistas o combativos a los servicios de inteligencia patronales o militares indica que algunos fueron más allá, algo que también complejiza el escenario y que requiere indagaciones sistemáticas (una exploración más reciente puede verse en Basualdo, 2013; una primera mención al tema de participación de sectores dirigentes en la represión puede encontrarse en Fernández, 1985).

Revisemos por último la cuestión de la oposición sindical a partir de la Jornada de Protesta de abril de 1979 convocada por un sector de esa dirigencia ortodoxa, la denominada "Comisión de los 25". Según Abós, y a partir de él para muchos otros, esa convocatoria constituyó un punto 
de inflexión en las relaciones entre la dirigencia sindical y el gobierno y se dice que a partir de esas jornadas la dirigencia sindical peronista ortodoxa habría actuado como antagonista del régimen militar desplegando una ofensiva hasta su retiro en diciembre de 1983.

En primer lugar es necesario destacar que las jornadas fueron convocadas solo por un grupo de esa dirigencia y que el sector mayoritario de la misma se mantuvo al margen agrupado o cercano al nucleamiento conocido como Comisión Nacional de Trabajo (CNT) lo que explica en parte que las mismas no tuvieran trascendencia nacional. La separación de los ortodoxos en tendencias sindicales (como la que representaban "los 25 " como grupo minoritario y la "CNT" y sus grupos satélites como mayoritarios) no implicó en un principio estrategias políticas distintas frente al gobierno, sino tácticas diferentes de presión sobre dos temas: cambios en el plan económico y normalización de las organizaciones. Ambos sectores se fusionaron incluso brevemente en 1980 formando una Central Única de Trabajadores Argentinos (CUTA) cuando el gobierno reglamentó la ley sindical a la que proyectaban oponerse.

Lo cierto es que la ley recibió un inicial rechazo, pero su aplicación avanzó y las tendencias críticas de "los 25" en 1979 quedaron en suspenso. Fue recién a partir de 1981 cuando "el debilitamiento sucesivo de los principales recursos de legitimación, el aumento de la oposición civil y la demora en la realización de los objetivos de máxima" provocaron como señala Canelo, la caída del gobierno "en un estado de verdadero colapso" (Canelo, 2008, p. 163) que reorganizó la estrategia sindical, especialmente la de ese sector. Esto porque la asunción del general Viola como reemplazo del general Videla no podía evitar las manifestaciones cada vez más explícitas de la crisis económica incluso cuando no se presentaba como alternativa la transición a la democracia. Fue allí que el sector de "los 25" nucleado tras el fracaso de la CUTA en la "CGT Brasil" comenzó a posicionarse como sector crítico del gobierno, consciente de que la acumulación de problemas iba hacia una crisis económica inevitable. Su orientación general fue reafirmarse en un tono cada vez más confrontacionista centrándose en la denuncia de los planes económicos y sus consecuencias a sabiendas de que necesitaba edificar su fortaleza entre las dirigencias sindicales nacionales y las bases obreras.

La asunción de Viola incluía promesas de apertura y tenía como uno de sus destinatarios predilectos a los sindicatos, pero los anuncios no lograron ganar adeptos y de allí en más el escenario político se debatió entre la interna militar contra Viola que finalmente impuso su salida y la creación de la "Multipartidaria", liderada por los partidos políticos que comenzaban a desvincularse del gobierno militar planteando que era necesario resolver 
"de alguna forma" de salida democrática. ${ }^{14}$ Recién allí, en 1981 y no desde abril de 1979, se constituyeron con mayor coherencia dos sectores dentro de la dirigencia sindical ortodoxa con dos estrategias políticas distintas frente al gobierno militar. La "CGT Brasil" atenta al deterioro general de la situación económica y social se propuso reorganizar su estrategia de confrontación convocando a una segunda jornada nacional de protesta con paralización de actividades, dos años y tres meses después de la primera, el 22 de julio de 1981. Como en 1979, la CNT actúo contra la medida con declaraciones que asociaban cualquier paro de actividades con un "mayor daño para el país" (La Nación 1 1/07/1981).

Este segundo paro tuvo una adhesión desigual a nivel nacional y no logró paralizar Buenos Aires ni el cordón industrial, lo que evidenciaba que la "CGT Brasil" no lideraba el escenario sindical y que las dirigencias ortodoxas no acompañaban de conjunto la estrategia crítica y confrontacionista. La evaluación de éste paro, que ha pasado inadvertido si se lo compara con la atención que recibió la jornada de 1979, suma evidencias a las impugnaciones hechas contra la propuesta de Abós y las ideas de un escenario general y continuo de confrontación sindical con la dictadura desde abril de 1979. ${ }^{15}$

Ese sector minoritario, la "CGT Brasil", continuó con su estrategia de confrontación convocando a una movilización -la primera del sindicalismo nacional desde 1976- por "paz, pan y trabajo" el 7 de noviembre de 1981 para asistir a una misa a la iglesia de San Cayetano, santo del trabajo en el culto católico. La movilización, como había sucedido con el paro, fue importante pero no masiva y el sindicalismo ortodoxo más allá de éste grupo se mantuvo al margen de la misma. La acción combinada de paro y movilización consolidaba el paso de las críticas al plan económico a aquellas que planteaban la necesidad de que el gobierno militar "se fuera" y dejara lugar para la institucionalización democrática del país, algo que

14 La Multipartidaria surgió como agrupamiento a propuesta del Partido Radical ante la falta de espacio para la actuación de los partidos políticos y como forma de presión para que el gobierno finalmente normalizara su actuación.

15 Exponente de quienes asumieron el que el último período de la dictadura revestía menos importancia, Pozzi le dedica en su libro solo tres carillas al período comprendido entre la asunción de Viola y el retiro militar (Pozzi, 2008, pp. 110-112). Esto no puede menos que ser considerado una falencia de éste importante trabajo, más cuando el mismo sostiene que la actividad obrera y sindical fue clave en "derrotar" a la dictadura y producir su reemplazo (ver Conclusiones, Pozzi, 2008). 
también planteó ese año en forma cada vez más insistente la Multipartidaria a partir de su Convocatoria al País. ${ }^{16}$

Quedaba de ese modo confirmando que uno de los dos sectores sindicales ortodoxos cifraba sus expectativas en el final del gobierno militar agilizando sus contactos externos (con la iglesia y los partidos políticos) y buscando ganar legitimidad, con la ayuda que le prestaba sin saberlo la posición mayoritaria de la dirigencia que se mantenía expectante del desarrollo de la interna militar que terminaría con la presidencia de Viola en forma abrupta. El sostenimiento de esas diferencias durante este corto período ganaría mayor significación en el marco de un descalabro general y sin precedentes de la situación económica, descalabró que puso al general del ejército Leopoldo Fortunato Galtieri en la presidencia como resultado de un autogolpe institucional. ${ }^{17}$

Fue el agotamiento de la "lucha contra la subversión" y la crisis de una reforma económica con consecuencias devastadoras lo que permitió que los sectores "duros" de las FFAA desplazaran el intento aperturista de Viola guiados por un proyecto actualizado para encauzar y continuar los planes refundacionales propuestos por el PRN en marzo de 1976. La reacción sindical dejó en evidencia la maduración de dos lecturas entre los ortodoxos: quienes apostaban a el retiro de las FFAA y la apertura democrática, criticando los planes económicos pero sin denunciar la inusitada represión que el PRN había desplegado para llevarlos a cabo, y quienes se veían

16 En la Convocatoria al País la Multipartidaria había planteado siete puntos que sintetizaban sus objetivos: el retorno al Estado de derecho; la normalización de las actividades políticas, gremiales y empresarias; la formulación de un plan político con un cronograma para la institucionalización del país; la elaboración de un plan de emergencia económica; la recuperación del salario real; el mejoramiento de la educación y el libre acceso a los medios de comunicación en poder del Estado (Multipartidaria, 1982; Quiroga, 1994, p. 324).

17 Novaro y Palermo indican que hacia fines de 1981 "el dólar había incrementado su paridad en el $80 \%$ y la inflación -del $200 \%$ anual- impactaba en el mercado interno en un círculo vicioso recesivo. Entre fines de 1980 y 1981 el PBI industrial había caído el 22\% y el PBI global el 9\%. La desocupación crecía y caían los salarios reales" (Novaro \& Palermo, 2003, p. 387). Canelo señala que el gobierno de Viola enfrentaba la crisis económica y la falta de apoyos sociales y políticos en su intento de reeditar el 'diálogo político' que había quedado suspendido en la presidencia de Videla (sobre el «diálogo político» ver González Bombal, 1991). A esto se sumaba la oposición abierta de los militares retirados, suma que provocó primero el alejamiento de Viola por "razones de salud" y desde diciembre su reemplazo por decisión de la Junta Militar (Canelo, 2008, pp. 164-176). 
aún "en la tremenda disyuntiva de enfrentarse o sumarse" al gobierno (ver "Por una navidad en Paz" documento de la "CGT Brasil" y "Comunicado de la Intersectorial CNT-20", en La Nación y Clarín 24/12/1981).

Las dirigencias políticas consideraban moderado y tardío el "diálogo político" que había intentado realizar Viola en 1981 y consideraba mucho más impracticable "la vuelta atrás" que pretendía conducir el general Galtieri en 1982. El gobierno tenía que hacer frente al "despertar de la sociedad civil" -como lo llamó Hugo Quiroga- ante una inmensa frustración social mientras crecía el impacto de los reclamos de los familiares de personas desaparecidas habían ido en aumento desde la visita de la Comisión Interamericana de Derechos Humanos (CIDH) en 1979, a lo que se sumaba la revelación de detalles sobre la suerte de algunos detenidos en lo que se denominó el "Show del Horror" (Feld, 2010) y los debates públicos sobre la existencia de "listas" de personas desaparecidas comprometiendo al gobierno en un sistema represivo que cuestionaba la explicación de los "excesos de subordinados". ${ }^{18}$

La determinación de la "CGT Brasil" de mantenerse en su línea crítica no había cambiado frente a la nueva presidencia sino que fue consolidándose. Recién entonces, a comienzos de 1982, se pueden encontrar evidencias de una presión en aumento de la base obrera sobre los dirigentes sindicales como la mencionada por Pozzi. ${ }^{19}$

18 La explicación de las desapariciones como "excesos de los subordinados" fue la primer explicación militar sobre lo sucedido, pero por distintas razones la misma no fue aceptada por las FFAA que consideraban que no debían darse explicaciones al respecto, ni por los grupos de familiares de las víctimas de la represión, que veían en la misma un intento de lograr impunidad.

19 Una muestra de que el proceso de oposición obrera frente a la carestía y el crecimiento de la desocupación había irrumpido en los gremios son las declaraciones de un miembro de la CNT a la sección de "panorama gremial" que editaba el diario Clarín donde decía: "si aquí comienzan los estallidos sociales como todos se empeñan en predecir, el problema será tanto para ellos, los militares, como para nosotros los dirigentes gremiales. Si los moderados comenzamos a ser desbordados en nuestras organizaciones habrá llegado el momento para que lamenten no habernos escuchado durante estos últimos seis años". En el mismo "panorama" se mencionaba que la preocupación era común entre los sindicatos de ambos agrupamientos donde surgían cada día más críticas a las conducciones que insistían en la concesión de "cheques en blanco" al gobierno militar (Clarín 25/01/1982) y aunque no es fácil precisar cuando había comenzado el desarrollo de esas críticas es improbable que se extendieran desde 1979. 
Fue ante la ola de suspensiones laborales y el agravamiento de la situación social que la "CGT Brasil" convocó a una nueva movilización ahora para "rechazar al gobierno militar" en el centro simbólico del poder político del país, la Plaza de Mayo, en el que enfrentó la disposición represiva del gobierno. Días después, el 2 de abril de 1982 el gobierno buscó y logró relegitimarse invadiendo Puerto Stanley y "recuperando" las islas Malvinas de manos británicas. Con esa acción la Junta Militar y el presidente de facto crearon un paréntesis nacionalista mayor pero comparable con el del mundial de fútbol de 1978 con resultados inmediatos desmesuradamente positivos. El escenario político se vio alterado por completo y la reacción sindical inicial fue de apoyo a la medida, aunque la misma no estuvo exenta de conflictos (como bien lo señala Carla Sangrilli, 2012). La derrota reconocida con la rendición militar del 14 de junio cerró abruptamente el paréntesis abierto por la guerra, dejando penosas y duraderas consecuencias amén del fracaso estrepitoso del intento de restauración de las condiciones de dominación interna que había llevado adelante Galtieri en su breve gobierno. El fracaso militar habría la crisis de postguerra marcada por una lenta descomposición del poder del PRN que derivaría en la disolución del triunvirato de las Fuerzas implicando el punto más alto de la crisis del régimen autoritario.

El relevo de Galtieri produjo la pública disolución de la Junta Militar dejando de allí en más al Ejército como responsable del gobierno nacional. El gobierno del general Bignone no sólo debía contener la crisis militar que había estallado con el final de la guerra, tenía que construir un acuerdo con la dirigencia política para organizar la "transición" o al menos los temas que los militares consideran esenciales de la misma. Ante esto la dirigencia política se mantuvo cauta, guiada por el convencimiento de que para la democracia era necesario un acuerdo entre civiles y militares, dividiéndose entre un sector moderado y uno más demandante al interior de la Multipartidaria pero sin "romper" el diálogo y las negociaciones con lo que quedaba del gobierno militar, algo que explica en parte el tiempo que pasó entre la derrota en la guerra y las elecciones democráticas de octubre del siguiente año (Yannuzzi, 1996).

En el ámbito gremial el transcurso de la guerra había profundizado las distintas orientaciones de los grupos ortodoxos. Para la "CGT Brasil" la derrota era una comprobación de que su estrategia de confrontación era correcta y seguía a tono con el movimiento político general como portadora de una de las voces más críticas, pero sin nunca ir más allá del consenso general y sin incorporar nuevas demandas manteniendo su distancia con el tema "de los derechos humanos" como lo habían hecho hasta entonces. El sector sindical de la CNT pensó la transición en términos de acuerdos para 
una concertación basada en la "reconciliación nacional" mientras aceleraba su adecuación a la ley sindical y se disponía a renovar su control de los sindicatos con la designación de "comisiones transitorias" y la realización de elecciones. Como para toda la dirigencia política, los largos meses que separan la derrota en la Guerra de Malvinas hasta la asunción del gobierno constitucional de Alfonsín fueron meses intensos y preparatorios de relaciones de fuerzas futuras.

Para los sindicatos esa "preparación" abarcó dos esferas separadas pero con vasos comunicantes: la que como dirigentes peronistas involucraba a los sindicalistas en la reorganización partidaria y la que estaba implicada en la dirección de la actividad sindical y su confirmación al mando de las organizaciones. El 22 de septiembre la "CGT Brasil" realizó su segunda movilización a Plaza de Mayo repitiendo el lema "Paz, Pan y Trabajo" mientras se resolvía la reorganización de las "62 Organizaciones Peronistas" que aparecería desde entonces como soporte del sector sindical liderado por Ubaldini bajo la dirección del metalúrgico Lorenzo Miguel. Buscando 'descomprimir' una situación que se veía cada vez más tensa desde el Ministerio de Trabajo a cargo de Héctor Villaveirán se anunció que no se darían aumentos de salarios pero sí se permitiría la "normalización" de veintisiete sindicatos, en un plan que avanzaba en el entendimiento de la dirigencia sindical con los militares. ${ }^{20}$

Las reacciones de la "CGT Brasil" mostraron hacia donde se orientaba la estrategia gubernamental pero no rechazaron la entrega de los sindicatos, sino que pidieron que la misma fuera hecha con "equidad" entre los dos grupos (La Nación y Clarín, 18/1 1/1982). De todos modos la "CGT Brasil" no cifró sus cálculos políticos en esas negociaciones y persistió en un plan de movilización que no hacía más que acompañar los conflictos sindicales por salarios y despidos que se reproducían en todo el país. El 21 de noviembre convocó una masiva movilización en una ciudad capital del interior del país, Rosario, y en diciembre anunció un nuevo paro, el tercero, para el 6 de diciembre de 1982. A éste se sumó por primera vez la ex CNT ahora denominada "CGT Azorpardo" y los apoyos fueron masivos mientras que la dirigencia política convocaba a su propia movilización para el 16 de ese mismo mes. La medida sindical tuvo un acatamiento estimado del $90 \%$ según el gobierno y se lo comparó, por su importancia, con las huelgas obreras contra el gobierno de Isabel Perón de junio de 1975

20 Este plan de 'normalización' fue denunciado por Raúl Alfonsín como un "pacto" entre sindicalistas y militares para garantizar el control de las estructuras sindicales y ayudar al peronismo en el proceso electoral a cambio de impunidad en relación con los delitos cometidos. 
(ver por ejemplo Clarín y La Nación 7/12/1982). No hubo transporte de pasajeros, atención comercial ni actividad fabril, no estuvieron abiertas las dependencias estatales, ni funcionaron con normalidad las áreas de salud, educación, bancaria, correos o la actividad marítima. Un detalle provincia por provincia indicó que la medida fue superior al $93 \%$ y en provincias como Córdoba o Rosario fue del 100\% (ver La Razón 6/12/1982 o Crónica 7/12/1982).

El comienzo de 1983 no fue más calmo. En medio de las primeras elecciones sindicales la "CGT Azopardo" anunció que su diálogo con el gobierno militar estaba terminado (Clarín, 21/01/1983) cuando ambos agrupamientos rechazaron los aumentos salariales propuestos. Cientos de despidos en varias automotrices y la huelga salvaje en la planta de Volkswagen se sumaban al anuncio de cierre de la empresa Swift Armour en Berisso y al incremento diario de conflictos en todo el país. La presión sobre un gobierno en franca retirada y sin más estrategia que intentar imponer su seguridad corporativa no podía ser mayor. Los agrupamientos sindicales convocaron entonces a un nuevo paro, el cuarto y último de carácter general del período dictatorial, esta vez para el 28 de marzo. El gobierno de Bignone lo declaró "ilegal", aislándose más aún, pues el éxito de la medida nacional fue indiscutido (Clarín y La Nación 29/03/1983).

La medida sin embargo no cortó el diálogo sindical con el gobierno y en un marco de negociaciones no públicas entre militares y referentes de ambos grupos sindicales se produjeron una serie de reformas a la ley 22.105 de Asociaciones Profesionales que tocaban los aspectos claves que habían sido rechazados por la dirigencia sindical, mientras que la adecuación a la nueva normativa abarcaba a más del $85 \%$ de las asociaciones sindicales del país (Zorzoli, 2016a). Las modificaciones incluían la posibilidad de administración sindical de las obras sociales y la autorización para realizar "actividades con fines de lucro", la existencia de organizaciones de tercer grado, legalizando a la CGT y la eliminación de las zonas de actuación que mencionaba la ley en 1979.

Eran concesiones de gran importancia y un retroceso evidente en términos de lo que el gobierno militar había intentado cambiar de la estructura sindical argentina, más si se tiene en consideración que se modificaba lo resuelto en una ley que se había discutido entre las tres Fuerzas Armadas por más de tres años. Esas reformas se hacían además en el marco de las últimas iniciativas militares, iniciativas cada vez más arrinconadas por la liberación de los "lazos autoritarios" y la ocupación por distintos sectores sociales del espacio público (Quiroga, 1994, p. 459).

Sobre el final del gobierno militar las direcciones sindicales aceleraron 
simultáneamente sus normalizaciones, controlando el proceso electoral y sentando las bases para una posición que se rebelará sólida apenas asuma el gobierno democrático. Justamente por eso es problemático afirmar que su poder corporativo y especialmente su posición al interior de los sindicatos había sufrido un debilitamiento que acompañaba linealmente la situación de retroceso de la clase obrera, como se expuso en la mayor parte de los estudios clásicos (con excepción de Pozzi que tendió a ver que los mismos se habían mantenido inalterados). El interrogante solo puede ser abordado si analizamos la refuncionalización de esa dirigencia sindical en el período sin fusiones inadecuadas y desde una reconstrucción que nos permita comprender el período de conjunto.

\section{Conclusiones}

Este artículo presentó un breve estado de la cuestión para entender cómo se construyeron las interpretaciones dominantes en las Ciencias Sociales sobre la situación de los trabajadores y sus organizaciones durante la última dictadura (1976-1983) y qué elementos de esas interpretaciones siguen vigentes en el campo de estudio. A partir de allí se buscó debatir con aspectos centrales de las mismas, que organizadas en torno a la idea de "derrota" o de "oposición" tendieron o bien a amalgamar lo sucedido a las direcciones sindicales del peronismo ortodoxo con otros sectores sindicales incluyendo a las y los perseguidos por el régimen militar y a la base obrera o a ignorar a las direcciones sindicales incorporándolas sólo cuando actuaron contra el régimen.

En este estudio, por el contrario, se parte de una identificación de los sectores sindicales con el fin de no fusionar inadecuadamente a los que son denominados generalmente como "combativos" o clasistas y la "dirigencia sindical peronista ortodoxa". Centrándonos en estos últimos y a partir de las críticas a las lecturas clásicas que analizamos, se abordaron algunos elementos que debieran considerarse para una nueva síntesis en los estudios sobre las organizaciones sindicales argentinas durante el gobierno militar (1976-1983). En primer lugar,

las impugnaciones a la periodización que planteara Abós obligan a avanzar en nuestro conocimiento del PRN en forma integrada, recuperando de esa manera no sólo lo acontecido durante la presidencia de Videla sino también las presidencias de facto de los generales Viola, Galtieri y Bignone. Esto posibilitará el análisis, que excede a éste artículo, de temas que fueron subestimados hasta hoy, como las intervenciones a las entidades gremiales, los conflictos con representación sindical durante el período, la normalización electoral y la reorganización interna de los sindicatos en el 
período post 1980 y la aplicación de la ley sindical y sus modificaciones.

Todos elementos trascendentes y necesarios para comprender la estructura sindical argentina post dictadura.

\section{Bibliografía}

ABÓS, A. (1984). Las organizaciones sindicales y el poder militar, 19761983. Buenos Aires: Centro Editor de América Latina.

ARRIAGA, A. E. (2012). "Avatares de una tradición combativa: Luz y Fuerza de Córdoba entre la normalización sindical y la lucha por la recuperación del convenio colectivo (1982-1989)" en VII Jornadas de Sociología UNLP. La Plata, Argentina.

BASUALDO, V. (2006a). "Complicidad patronal-militar en la última dictadura argentina: los casos de Acindar, Astarsa, Dálmine Siderca, Ford, Ledesma y Mercedes Benz" en Revista Engranajes de la Federación de Trabajadores de la Industria y Afines (FETIA), 5.

BASUALDO, V. (2006b). "Dictadura militar, sindicalismo combativo y relaciones internacionales: apuntes para una historia reciente de los trabajadores" en Antología: A 30 años del golpe. Buenos Aires, Central de Trabajadores Argentinos.

BASUALDO, V. (2007). "Una aproximación al exilio obrero y sindical" en P. Yankelevich \& S. Jensen (eds.), Exilios: destinos y experiencias bajo la dictadura militar. Buenos Aires, Libros del Zorzal, pp. 187-208.

BASUALDO, V. (2008). Los delegados y las comisiones internas en la historia argentina: una mirada de largo plazo, desde sus orígenes hasta la actualidad. DGB Bildungswerk.

BASUALDO, V. (2010). "The ILO and the Argentine Dictatorship (19761983)" en J. van Daele (ed.), ILO histories essays on the International Labour Organization and its impact on the world during the twentieth century. Bern; New York: Peter Lang, pp. 401-413.

BASUALDO, V. (2013). "Aportes para el análisis del papel de la cúpula sindical en la represión a los trabajadores en la década de 1970" en $\mathrm{H}$. Verbitsky \& J. P. Bohoslavsky (eds.), Cuentas pendientes: los cómplices económicos de la dictadura. Buenos Aires, Argentina: Siglo Veintiuno Editores, pp. 235-253.

BESSE, J., \& WLOSKO, M. (2013). "Presentación: Memorias del trabajo, trabajos de la memoria" en J. BESSE, E. CRENZEL, L. MESSINA, \& M. WLOSKO (eds.), Memoria y trabajadores (Vol. 2). Remedios de Escalada: De la UNLa - Universidad Nacional de Lanús, pp. 9-21. 
BIALAKOWSKY, A., MICIELI, C., \& KOGAN, H. (1986). "Articulaciones laborales en la crisis del sindicalismo argentino (1976-1981)" en F. ZAPATA (Ed.), El Sindicalismo Latinoamericano en los 80. Santiago de Chile: Comisión de Movimientos Laborales de la CLACSO.

BIEBER, L. E. (1982). "El movimiento laboral argentino a partir de 1976. Observaciones al trabajo de Francisco J. Delich" en P. WALDMANN \& E. GARZÓN VALDÉS (Eds.), El poder militar en la Argentina (1976-1981) Frankfurt: Vervuert, pp. 116-122.

BRENNAN, J. P., \& GORDILLO, M. (2008). Córdoba rebelde: el cordobazo, el clasismo y la movilización social. La Plata: De la Campana.

BRETAL, E. (2011). "Memorias y experiencias de obreros/as de la carne sobre una época «brava»: "los compañeros que se iban yendo» y la «degradación» del Swift en Berisso" en Theomai, n² 24, pp. 43-69

CANELO, P. (2008). El proceso en su laberinto: la interna militar de Videla a Bignone. Buenos Aires, Prometeo.

CANELO, P. (2016). La política secreta de la última dictadura. Buenos Aires, Edhasa.

CRENZEL, E. (2008). La historia política del Nunca más : La memoria de las desapariciones en la Argentina. Buenos Aires: Siglo XXI.

CRENZEL, E. (2013). "Representaciones sobre los obreros desaparecidos: La lectura del Nunca Más" en J. BESSE, E. CRENZEL, L. MESSINA, \& M. WLOSKO (eds.), Memoria y trabajadores (Vol. 2). Remedios de Escalada: De la UNLa - Universidad Nacional de Lanús.

DAWYD, D. (2011). Sindicatos y política en la Argentina del Cordobazo: el peronismo entre la CGT de los Argentinos y la reorganización sindical : 1968-1970. Buenos Aires: Pueblo Heredero Editorial.

DAWYD, D. (2014). "Raimundo Ongaro: dirigente sindical. Trayectoria de un peronista combativo en contextos de hostilidad (Argentina, 19661983)". Abordajes. Revista de Trabajo Social, n² 2 , pp. $21-53$.

DELICH, F. (1982). Después del diluvio, la clase obrera. En Argentina, hoy (pp. 129-150). México: Siglo Veintiuno Editores.

DICÓSIMO, D. (2006). "Dirigentes sindicales, racionalización y conflictos durante la última dictadura militar". Entrepasados - Programa Buenos Aires de Historia Política del Siglo XX, pp. 1-19.

DICÓSIMO, D., \& CARMINATI, A. (2013). "Sabotaje a la dictadura. Un estudio sobre las formas de sabotaje industrial durante la última dictadura militar en el Gran Rosario y el Centro Sudeste bonaerense (1976-1983)". Anuario IEHS: Instituto de Estudios histórico sociales, n 28, pp. 257-278. 
DICÓSIMO, D., \& SOUL, M. J. (2013). "La representación sindical en la Argentina durante el siglo XX. Aportes para una reflexión desde la dinámica institucional y social". Anuario IEHS, n ${ }^{\circ} 28$, pp. 251-255.

FELD, C. (2010). "La representación de los desaparecidos en la prensa de la transición: el "show del horror»" en E. CRENZEL (ed.), Los desaparecidos en la Argentina. Memorias, representaciones e ideas (1983-2008). Buenos Aires: Editorial Biblios, pp. 25-41.

FERNÁNDEZ, A. (1985). Las prácticas sociales del sindicalismo: 19761982. Buenos Aires, Centro Editor de América Latina.

GALLITELLI, B., \& THOMPSON, A. (1982). Sindicalismo y regímenes militares en Argentina y Chile. Amsterdam: CEDLA.

GHIGLIANI, P. (2011). "El conflicto de Luz y Fuerza de 1976-1977: ensayo de interpretación" en IV Seminario Internacional Políticas de la Memoria, Buenos Aires.

GONZÁLEZ BOMBAL, I. (1991). El diálogo político: la transición que no fue. Buenos Aires: CEDES.

GORDILLO, M. (2013). "La disputa por la democratización sindical en los '80". Desarrollo Económico, Vol. 53, n²09-210, pp. 143-167.

GORDILLO, M. (2016). "¿Cómo enfrentar a las burocracias sindicales? Algunas estrategias democratizadoras en los 80". Revista Archivos de Historia del Movimiento Obrero y la Izquierda, $\mathrm{n}^{\circ}$ 8, pp. 55-77.

IRAMAIN, L. D. (2014). "La política laboral de la última dictadura cívico-militar argentina en el ámbito de las empresas públicas. Los casos de ENTEL, Gas del Estado y Ferrocarriles Argentinos (1976-1983)". Anuario IEHS: Instituto de Estudios histórico sociales, n² 29, pp. 71-96.

JAMES, D. (2006). Resistencia e integración: el peronismo y la clase trabajadora argentina, 1946-1976. (L. Justo, Trad.). Buenos Aires: Siglo Veintiuno Editores.

LÓPEZ, E., \& PION-BERLIN, D. (1996). Democracia y cuestión militar. Buenos Aires: Universidad Nacional de Quilmes.

LORENZ, F. (2007). Los zapatos de Carlito: una historia de los trabajadores navales de Tigre en la década del setenta. Buenos Aires: Grupo Editorial Norma.

LORENZ, F. (2013). Algo parecido a la felicidad: Una historia de la lucha de la clase trabajadora durante la década del setenta [1973-1978]. Buenos Aires: Edhasa.

MASSANO, J. P. (2012). "El movimiento obrero sindicalizado en el inicio de la postdictadura: una reconstrucción del proceso de oposición al 
proyecto de reordenamiento sindical de (1983-1984)" en VI Jornadas de Trabajo sobre Historia Reciente (UNL). Universidad Nacional del Litoral: VI Jornadas de Trabajo sobre Historia Reciente (UNL).

Ministerio de Justicia y Derechos Humanos de la Nación; Centro de Estudios Legales y Sociales; Facultad Latinoamericana de Ciencias Sociales. (2015). Responsabilidad empresarial en delitos de lesa humanidad. Buenos Aires, Ministerio de Justicia y Derechos Humanos de la Nación; Centro de Estudios Legales y Sociales; Facultad Latinoamericana de Ciencias Sociales.

MOLINARO, L. (2013). Demonización y reconciliación nacional : Representaciones sobre la violencia política setentista en los primeros años de la transición democrática. Buenos Aires: Colisión.

MOLINARO, L. (2016). "El reposicionamiento de la burocracia sindical en el ocaso del "Proceso»". Revista Archivos de Historia del Movimiento Obrero y la lzquierda, $n^{\circ} 8$, pp. 33-55.

Multipartidaria. (1982). La propuesta de la Multipartidaria. Buenos Aires: El Cid Editor/Fundación para la Democracia en Argentina.

NOVARO, M., \& PALERMO, V. (2003). La dictadura militar, 1976-1983: del golpe de estado a la restauración democrática. Buenos Aires: Paidós.

PEREZ, M. E., \& DI MARÍA, A. (2007). "La apropiación de niños por motivos políticos como práctica genocida" en Actas del V Encuentro sobre Genocidio. Genocidio y Diferencia, organizado por el Grupo de Estudio de Genocidio del Centro Armenio y la Cátedra Libre de Estudios Armenios de la Facultad de Filosofía y Letras de la UBA. Buenos Aires.

POZZI, P. (1988). Oposición obrera a la dictadura, 1976-1982. Buenos Aires, Editorial Contrapunto.

POZZI, P. (2008). La oposición obrera a la dictadura : 1976-1982. Buenos Aires: Imago Mundi.

QUIROGA, H. (1994). El tiempo del «proceso»: conflictos y coincidencias entre políticos y militares, 1976-1983. Rosario, Argentina: Editorial Fundación Ross.

RODRÍGUEZ, L. G. (2008). "Los trabajadores del sector público durante la dictadura. El caso de los docentes (1976-1983)". Cuadernos del Sur - Historia, $\mathrm{n}^{\circ} 37$, pp. 121-138.

ROUQUIÉ, A. (1982). "Hegemonía militar, estado y dominación social" en Rouquié, A. (ed.) Argentina, hoy. México: Siglo Veintiuno Editores, pp. 11-50. SANGRILLI, C. (2010). "La normalización sindical entre la dictadura y los comienzos de la democracia (1979-1984)". Estudios Sociales, n³9, pp. 147-170. 
SANGRILLI, C. (2012). "La combativa CGT en tiempos de la guerra de Malvinas (1982)". Revista Escuela de Historia, n 11, pp. 1-23.

SCHNEIDER, A. (2005). Los compañeros: trabajadores, izquierda y peronismo, 1955-1973. Buenos Aires: Imago Mundi.

VILLARREAL, J. (1985). "Los hilos sociales del poder" en E. JOZAMI, P. PAZ, \& J. VILLARREAL (eds.), Crisis de la dictadura argentina: política económica y cambio social, 1976-1983 Buenos Aires, Siglo Veintiuno Argentina Editores, pp. 201-283.

WALDMANN, P., \& GARZÓN VALDÉS, E. (1982). El poder militar en la Argentina (1976-1981). Frankfurt: Vervuert.

WERNER, R., \& AGUIRRE, F. (2007). Insurgencia obrera en la Argentina, 1969-1976: clasismo, coordinadoras interfabriles y estrategias de la izquierda. Buenos Aires: Ediciones IPS.

YANNUZZI, M. DE LOS A. (1996). Política y dictadura: los partidos políticos y el «proceso de reorganización nacional» 1976-1982. Rosario, Editorial Fundación Ross.

ZORZOLI, L. (2015). "La normativa sindical entre la dictadura y el alfonsinismo, propuesta de sistematización" en A. SCHNEIDER \& P. GHIGLIANI (Eds.), Clase obrera, sindicatos y Estado. Argentina (1955-2010). Buenos Aires, Imago Mundi, pp. 147-169.

ZORZOLI, L. (2016a). Los sindicatos y el gobierno militar. Un estudio de sus relaciones a partir de la participación en la Organización Internacional del Trabajo (1976-1983). Tesis para optar por el título de Doctora en Ciencias Sociales, Facultad de Ciencias Sociales, Universidad de Buenos Aires, Buenos Aires, Argentina.

ZORZOLI, L. (2016b). " «Operativo Ginebra». La dirigencia sindical ante la instalación internacional de la dictadura militar (1976)". Revista Archivos de Historia del Movimiento Obrero y la lzquierda, $\mathrm{n}^{\circ}$ 8, pp. 12-32. 